\title{
THE REALM OF BIOCHEMISTRY
}

(I) Outlines of Biochemistry: the Organic Chemistry and the Physicochemical Reactions of Biologically Important Compounds and Systems

By Prof. Ross Aiken Gortner. Second edition. Pp. $x x+1017$. (New York: John Wiley and Sons, Inc.; London: Chapman and Hall, Ltd., 1938.) 30s. net.

\section{(2) Organic and Bio-chemistry}

By Prof. R. H. A. Plimmer. Sixth edition. Pp. $x+623$. (London, New York and Toronto : Longmans, Green and Co., Ltd., 1938.) 21s. net.

(3) Biochemistry for Medical Students

By Dr. Willian Veale Thorpe. Pp. viii +457 . (London : J. and A. Churchill, Ltd., 1938.) 12s. $6 d$.

$\mathrm{I}^{\mathrm{T}}$ is welcome to have under review at the same time three such excellent books on biochemistry dealing with different stages through which students in this science will be expected to pass.

The first two have passed the first edition, and Gortner's book is the second edition of the wellknown text-book which has been brought up to date and amplified in accordance with modern needs.

The second book, by Plimmer, is the sixth edition of this well-known treatise and has also been amplified and brought up to date.

The third book is a student's text-book which has been written by a newcomer in this field, and deals with such matters as may be required by the medical student.

Time was not so very long ago when biochem. istry was treated as a section of physiology, and so far as science was concerncd remained in relation to organic chemistry a mass of empirical data which seemed to bear little or no relation one to the other.

The books under review indicate that the physiological side of biochemistry is rapidly diminishing in importance and the subject is being based more and moze strongly on organic chemistry with its strictness of formule and diction. In fact, there seems to be no hope of ever reaching any knowledge of what underlies the chemistry of life unless biochemistry is approached from the pure science of organic chemistry. It is pleasant to note that in the three books under review the basis of organic chemistry is held in mind continuously and wherever possible the line followed is that of established reason rather than of empiricism. Plimmer's book, and that by Gortner, are text-books of the science which deal in detail with the whole subject; that by W. V. Thorpe contains a wealth of interesting detail. It restricts itself to that which the medical student requires, and the student who has acquired the knowledge contained in this book will not have laboured in vain.

J. F. T.

\section{THE MANIPULATION OF GASES}

Experimental Methods in Gas Reactions

By Dr. A. Farkas and Dr. H. W. Melville. Pp. $\mathrm{xv}+390$. (London: Macmillan and Co., Ltd., 1939.) 30s. net.

7 HIS treatise will become a standard work and a necessary reference book for all physicists and chemists engaged in conducting experimental researches with gases. Its usefulness is enhanced by the fact that the authors have had actual practical experience with many of the devices and apparatus described, and are therefore well qualified to point out the limitations, defects and advantages of alternative methods of procedure. The arduous labour of collesting from scattered sources information hitherto imperfectly catalogued has resulted in a valuable contribution to science in a very practical form. The references are very numerous, the diagrams clear, and the printing, especially of the formule, admirable. The mathematical relations quoted in the text have in many cases been deduced from first principles, ard theoretical questions of sufficient fundamental importance have not been left unexplained.

In the preface the authors state: "The book is designed mainly to give a reasonably complete account of the methods of investigating all types of gaseous reactions together with sufficient theory, in order that there should be the minimum gap between theory and practice. While it is intended that the beginner will benefit from the work, the text is arranged in such a way that it may serve as a book of reference for those chemists and physicists engaged in dealing with gas reactions, with high vacua, or with any investiga- 